\title{
(2) OPEN ACCESS \\ Comparative analysis of major incident triage tools in children: a UK population-based analysis
}

\author{
James Vassallo (1) , 1,2 Saisakul Chernbumroong, ${ }^{3,4}$ Nabeela Malik, ${ }^{3,4}$ Yuanwei $\mathrm{Xu}^{4}$ \\ Damian Keene, ${ }^{5}$ George Gkoutos, ${ }^{6,7}$ Mark D Lyttle (D) , ${ }^{8}$ Jason Smith (D) , ${ }^{2,9}$ in \\ collaboration with PERUKI (Paediatric Emergency Research in the UK and Ireland)
}

\begin{abstract}
Handling editor Kirsty Challen
Additional supplemental material is published online only. To view, please visit the journal online (http://dx.doi. org/10.1136/emermed-2021211706)
\end{abstract}

For numbered affiliations see end of article.

\section{Correspondence to} Dr James Vassallo, Institute of Naval Medicine, Gosport, P012 2DL, UK;

jamie.vassallo@nhs.net

Received 25 May 2021 Accepted 8 October 2021

Check for updates

(c) Author(s) (or their employer(s)) 2021. Re-use permitted under CC BY-NC. No commercial re-use. See rights and permissions. Published by BMJ.

\begin{tabular}{l}
\hline To cite: Vassallo J, \\
Chernbumroong S, \\
Malik N, et al. \\
Emerg Med J Epub ahead \\
of print: [please include Day \\
Month Year]. doi:10.1136/ \\
emermed-2021-211706
\end{tabular}

\section{ABSTRACT}

Introduction Triage is a key principle in the effective management of major incidents. There is currently a paucity of evidence to guide the triage of children. The aim of this study was to perform a comparative analysis of nine adult and paediatric triage tools, including the novel 'Sheffield Paediatric Triage Tool' (SPTT), assessing their ability in identifying patients needing life-saving interventions (LSIs).

Methods A 10-year (2008-2017) retrospective database review of the Trauma Audit Research Network (TARN) Database for paediatric patients ( $<16$ years) was performed. Primary outcome was identification of patients receiving one or more LSIs from a previously defined list. Secondary outcomes included mortality and prediction of Injury Severity Score (ISS) >15. Primary analysis was conducted on patients with complete prehospital physiological data with planned secondary analyses using first recorded data. Performance characteristics were evaluated using sensitivity, specificity, undertriage and overtriage.

Results 15133 patients met TARN inclusion criteria. 4962 (32.8\%) had complete prehospital physiological data and 8255 (54.5\%) had complete first recorded physiological data. The majority of patients were male $(69.5 \%)$, with a median age of 11.9 years. The overwhelming majority of patients (95.4\%) sustained blunt trauma, yielding a median ISS of 9 and overall, 875 patients $(17.6 \%)$ received at least one LSI. The SPTT demonstrated the greatest sensitivity of all triage tools at identifying need for LSI (92.2\%) but was associated with the highest rate of overtriage $(75.0 \%)$. Both the Paediatric Triage Tape (sensitivity 34.1\%) and JumpSTART (sensitivity 45.0\%) performed less well at identifying LSI. By contrast, the adult Modified Physiological Triage Tool-24 (MPTT-24) triage tool had the second highest sensitivity $(80.8 \%)$ with tolerable rates of overtriage (70.2\%).

Conclusion The SPTT and MPTT-24 outperform existing paediatric triage tools at identifying those patients requiring $\mathrm{LSIs}$. This may necessitate a change in recommended practice. Further work is needed to determine the optimum method of paediatric major incident triage, but consideration should be given to simplifying major incident triage by the use of one generic tool (the MPTT-24) for adults and children.

\section{INTRODUCTION}

Major incidents occur worldwide on a regular basis, when existing resources are outstripped due to the

\section{Key messages}

What is already known on this subject

- Triage is a key principle in the effective management of major incidents. There is currently a paucity of evidence surrounding the use of existing paediatric major incident tools.

- In the UK, two methods of paediatric major incident triage exist, the Paediatric Triage Tape (PTT) and the JumpSTART method. In previous studies, they have demonstrated less than $50 \%$ sensitivity at identifying children in need of lifesaving interventions.

- Recently, the 'Sheffield Paediatric Triage Tool' (SPTT) was developed, having been derived from the adult Modified Physiological Triage Tool-24 (MPTT-24) score used in both civilian and military practice in adults.

What this study adds

- This study performed a comparative analysis of nine adult and paediatric-specific triage tools using a UK paediatric trauma registry population.

- The PTT and JumpSTART perform poorly ( $45 \%$ sensitivity) in this paediatric trauma registry population. The SPTT and the existing adult triage tool, the MPTT-24, outperform all methods but both have high levels of overtriage.

- While the SPTT was more sensitive than the MPTT-24, consideration should be given to simplifying major incident triage by the use of a single generic tool (MPTT-24) for both adults and children.

number, type, severity or location of casualties, necessitating additional support. ${ }^{1}$ Triage is a key principle in effectively managing major incidents, whereby patients are prioritised on the basis of their clinical acuity, typically using a simple physiological assessment as part of a triage tool. ${ }^{1}$ While existing triage tools have been derived and validated using mortality and injury severity as outcomes of interest, neither of these reflect the acuity of the patient or the need for a life-saving intervention. ${ }^{2-5}$

In the UK, two paediatric major incident triage tools exist: the Paediatric Triage Tape (PTT, ${ }^{6}$ for prehospital use in patients under 12 years) and JumpSTART $^{7}$ (for in-hospital use in patients under 
9 years) Both are paediatric adaptations of adult triage tools (Major Incident Medical Management and Support (MIMMS) Triage Sieve, and Simple Triage and Rapid Treatment (START), respectively ${ }^{18}$ ) and use a stepwise approach to triage; the PTT ${ }^{6}$ uses physiological variables based on the child's length as a proportionate surrogate for age, and JumpSTART ${ }^{7}$ uses a single respiratory rate threshold. Within the UK, one further alternative method of paediatric triage has been proposed. This is the Sheffield Paediatric Triage Tool (SPTT), a paediatric adaptation of the adult Modified Physiological Triage Tool-24 (MPTT-24) (online supplemental figure 1). The SPTT has undergone practical testing within a simulated paediatric major incident, where it correctly triaged all patients, thereby representing a potentially viable alternative to the PTT and JumpSTART (C O'Connell, personal communication, 25 January 2020).

Extensive research has been conducted in adult major incident triage, leading to the development and implementation of the MPTT- $24^{9}$ into both UK military pre-hospital and civilian in-hospital practice (NHS Clinical Guidelines for Major Incidents). ${ }^{10}$ By contrast, there is a paucity of evidence surrounding paediatric major incident triage tools. Limited studies have evaluated the performance of existing triage tools in identifying the need for life-saving interventions, and these have demonstrated poor performance of existing UK methods. ${ }^{211}$ Perhaps the greatest challenge in designing a fit-for-purpose paediatric major incident tool is the determination of appropriate physiological thresholds denoting the need for intervention. Normal ranges are wide and change with age, leading to potential for confusion in those performing triage in this high stakes, high stress event. ${ }^{612}$

Ideally, any study examining the performance of triage tools should be tested in the environment in which they are to be used, (ie, within the major incident context). However, due to the unpredictability of major incidents and associated ethical implications, the feasibility of such an assessment is very low. As a result, trauma registries, which contain high numbers of seriously injured patients, are often used as a proxy to examine the performance accuracy of such triage tools. ${ }^{213-15}$

The aim of this study was to compare the performance of the MPTT-24 and its paediatric derivative, the SPTT with existing adult and paediatric triage tools using the UK Trauma Audit and Research Network (TARN) Database. The primary outcome was their performance accuracy in identifying paediatric patients in need of a life-saving intervention (priority one patients). ${ }^{16}$

\section{METHODS}

A retrospective database review was undertaken using the TARN Database for a 10-year period (1 January 2008-31 December 2017). All paediatric (age $<16$ years) trauma patients, meeting TARN inclusion criteria (online supplemental file 1), were considered eligible.

TARN is the largest trauma registry in Europe, and collects data on all patients sustaining moderate and severe trauma admitted to trauma-receiving hospitals in England and Wales. Patients are included if they fulfil one of the following criteria: admission to a critical care area; transfer for specialist care; death or hospital admission for $>3$ nights. ${ }^{14}$ Information is submitted electronically by trained hospital coordinators and captures data from injury through to discharge, including interventions. Patients declared dead at scene and not conveyed to hospital are not recorded; these were therefore not included in our analyses. Owing to the nature of the TARN registry and its inclusion criteria, patients were assumed to be non-ambulant.
Patients receiving one or more life-saving interventions based on a previously defined list $^{16}$ (with adaptations for paediatric fluid resuscitation in keeping with APLS ${ }^{12}$ ) were considered to be priority one (online supplemental table 1).

Primary analysis for all outcomes of interest was conducted on patients with complete prehospital physiological data. A planned secondary analysis was conducted using first recorded physiological data, whether performed in the prehospital or ED setting. Patients were categorised as priority one, or not priority one, using available paediatric (PTT, ${ }^{6}$ JumpSTART $^{7}$ and SPTT) and adult (MPTT-24 (including airway opening manoeuvre), ${ }^{917}$ National Ambulance Service Medical Directors $(\mathrm{NASMeD})$ Triage Sieve, ${ }^{18}$ Modified Simple Triage and Rapid Treatment, ${ }^{19}$ Careflight, ${ }^{14}$ MIMMS Triage Sieve, ${ }^{1}$ Rapid Assessment of Mentation and Pulse (RAMP) ${ }^{20}$ ) triage tools. In keeping with the design of the JumpSTART and PTT, once a patient reached a predefined age ( 8 and 12 years, respectively), they were then triaged by the corresponding adult triage tool (START and MIMMS Triage Sieve, respectively ${ }^{118}$ ). A comparison of the different triage tools is shown in table 1. Assumptions made for the categorisation of triage tools are described in online supplemental file 2 .

The primary outcome was the correct determination of priority one status (requirement for life-saving intervention) in paediatric patients (defined as under 16 years) with subgroup analyses conducted for the age ranges $<1$ year, $1-2$ years, $2-5$ years, 5-12 years, $12-16$ years, $<12$ years, $<16$ years.

Secondary outcome measures included the prediction of major trauma (defined as Injury Severity Score (ISS) >15) and mortality.

\section{Missing data}

A comparison was made between patients with complete data and those missing prehospital physiological data, to explore for systematic differences in ISS, mortality and need for lifesaving intervention. Performing a list-wise deletion on patients without complete data can introduce systematic errors, therefore multiple imputation was used on the first recorded physiological data set in order to derive imputed data. Details of the modelling strategy are provided in online supplemental file 3 . In keeping with the main methods, a comparative analysis was then performed on the imputed data set.

\section{Statistical analysis}

Statistical analysis was performed to derive the sensitivity and specificity of the triage tools in detecting the outcomes of interest. Undertriage and overtriage were calculated in keeping with previously published methods on trauma triage (1-sensitivity and 1-positive predictive value). ${ }^{21} 22 \mathrm{~A} \mathrm{X}^{2}$ test was used to evaluate for statistical significance in categorical variables between included and excluded groups. Data distribution between the first recorded physiology group and the imputed data group was compared using a Kolmogorov-Smirnov test. Python software (V.3.7, Scotts Valley California, 2009) and R software (V.3.6, R Core Team, New Zealand, 2000) were used for data processing and analysis.

\section{Patient and public involvement}

Patients and/or the public were not involved in the design, or conduct, or reporting or dissemination plans of this research.

\section{RESULTS}

During the study period, 15133 patients aged under 16 years met TARN inclusion criteria, of which 4962 (32.8\%) had complete 
Table 1 Triage tool comparison

\begin{tabular}{|c|c|c|c|c|c|c|c|}
\hline \multirow[b]{2}{*}{ Tool } & \multicolumn{7}{|l|}{ Tool components } \\
\hline & 1st step & 2nd step & 3rd step & 4th step & 5th step & 6th step & 7th step \\
\hline $\begin{array}{l}\text { Paediatric Triage } \\
\text { Tape (PTT) }\end{array}$ & $\begin{array}{l}<10 \mathrm{~kg} \text { : } \\
\text { alert and moving all limbs } \\
11-18 \mathrm{~kg} \text { : } \\
\text { alert and moving all limbs } \\
\text { or walking } \\
>19 \mathrm{~kg} \text { : } \\
\text { walking }\end{array}$ & $\begin{array}{l}\text { Breathing } \\
\text { (open airway } \\
\text { if required) }\end{array}$ & $\begin{array}{l}\text { RR: } \\
<10 \mathrm{~kg}: \\
<20 \text { or }>50 \\
11-18 \mathrm{~kg}: \\
<15 \text { or }>45 \\
>19 \mathrm{~kg}: \\
<10 \text { or }>30\end{array}$ & Capillary refill: $<2 \mathrm{~s}$ & $\begin{array}{l}\text { HR: } \\
<10 \mathrm{~kg}: \\
<90 \text { or }>180 \\
11-18 \mathrm{~kg}: \\
<80 \text { or }>160 \\
>19 \mathrm{~kg}: \\
<70 \text { or }>140\end{array}$ & & \\
\hline JumpSTART $^{7}$ & Walking? & $\begin{array}{l}\text { Breathing } \\
\text { (open airway } \\
\text { if required) }\end{array}$ & $\begin{array}{l}\text { If apnoeic, assess } \\
\text { for pulse. If } \\
\text { present, give } 5 \\
\text { rescue breaths. }\end{array}$ & $\mathrm{RR}:<15$ or $>45$ & Palpable pulse? & $\begin{array}{l}\text { Conscious level } \\
\text { assessment } \\
\text { (AVPU)§ }\end{array}$ & \\
\hline $\begin{array}{l}\text { Sheffield Paediatric } \\
\text { Triage Tool (SPTT) }\end{array}$ & $\begin{array}{l}\text { Catastrophic } \\
\text { haemorrhage? }\end{array}$ & Walking? & $\begin{array}{l}\text { Breathing } \\
\text { (open airway if } \\
\text { required) }\end{array}$ & $\begin{array}{l}\text { If apnoeic, assess for } \\
\text { pulse. If present, give } 5 \\
\text { rescue breaths. }\end{array}$ & Responds to voice? & $\begin{array}{l}\text { Age-appropriate } \\
\text { RR?* }\end{array}$ & $\begin{array}{l}\text { Age- } \\
\text { appropriate } \\
\text { HRt }\end{array}$ \\
\hline Careflight $^{14}$ & Walking? & $\begin{array}{l}\text { Obeys } \\
\text { commands? }\end{array}$ & $\begin{array}{l}\text { Palpable radial } \\
\text { pulse? OR Breathes } \\
\text { with open airway? }\end{array}$ & - & - & - & - \\
\hline $\begin{array}{l}\text { Major Incident } \\
\text { Medical } \\
\text { Management and } \\
\text { Support (MIMMS) } \\
\text { Triage Sieve }^{1}\end{array}$ & Walking? & $\begin{array}{l}\text { Breathing } \\
\text { (open airway } \\
\text { if required) }\end{array}$ & $\mathrm{RR}:<10$ or $\geq 30$ & $\mathrm{HR}:>120$ & - & - & - \\
\hline $\begin{array}{l}\text { Modified } \\
\text { Physiological } \\
\text { Triage Tool } 24 \\
\text { (MPTT-24) } \ddagger^{91017}\end{array}$ & $\begin{array}{l}\text { Catastrophic } \\
\text { haemorrhage? }\end{array}$ & Walking? & $\begin{array}{l}\text { Breathing? Open } \\
\text { airway if required. }\end{array}$ & Responds to voice? & $\mathrm{RR}:<12$ or $\geq 24$ & $H R: \geq 100$ & - \\
\hline $\begin{array}{l}\text { Modified Simple } \\
\text { Triage and Rapid } \\
\text { Treatment }^{19}\end{array}$ & Walking? & $\begin{array}{l}\text { Spontaneous } \\
\text { breathing }\end{array}$ & $\mathrm{RR}:>30$ & Radial pulse absent & Obeys commands & - & - \\
\hline $\begin{array}{l}\text { National Ambulance } \\
\text { Service Medical } \\
\text { Directors (NASMeD) } \\
\text { Triage Sieve }^{18}\end{array}$ & Catastrophic haemorrhage & $\begin{array}{l}\text { Are they } \\
\text { injured? }\end{array}$ & Walking? & $\begin{array}{l}\text { Breathing? Open } \\
\text { airway if required }\end{array}$ & Unconscious & $\mathrm{RR}:<10$ or $\geq 30$ & $\begin{array}{l}\text { Pulse }>120 \text { or } \\
\text { capillary refill } \\
>2 \mathrm{~s}\end{array}$ \\
\hline $\begin{array}{l}\text { Rapid Assessment } \\
\text { of } \\
\text { Mentation and } \\
\text { Pulse (RAMP) }{ }^{20}\end{array}$ & $\begin{array}{l}\text { Casualty without signs of } \\
\text { obvious death }\end{array}$ & $\begin{array}{l}\text { Casualty } \\
\text { follows } \\
\text { commands }\end{array}$ & $\begin{array}{l}\text { Radial pulse } \\
\text { present? }\end{array}$ & - & - & - & - \\
\hline
\end{tabular}

*RR: $<1: 30-40,1-2: 25-25,2-5: 25-30,5-12: 20-25,>12: 15-20$.

†HR: $<1: 110-160,1-2: 100-150,2-5: 95-140,5-12: 80-120,>12: 60-100$.

¥MPTT-24 was updated in 2018 following consultation with NHS England to explicitly include the 'open airway' step as part of the breathing assessment. ${ }^{17}$ This current version is currently in use in both UK military and civilian in-hospital practice (within the NHS Clinical Guidelines for Major Incidents). ${ }^{10}$

§AVPU: Alert, responds to Voice, responds to Pain, Unconscious.

prehospital physiological data and 8255 (54.5\%) had complete first recorded physiological data (at scene and ED). A study flow diagram is shown in figure 1 with age group breakdown detailed in table 2. Median age was 11.9 years (IQR 8.0-14.2), and the majority of patients were male (69.5\%). Median ISS was 9 (IQR 9-17) with low overall mortality $(1.1 \%)$. Blunt trauma predominated (95.4\%), with motor vehicle collisions (49.6\%) and low falls $(23.9 \%)$ the leading mechanisms of injury. In total, 875 (17.6\%) of patients with complete prehospital physiological data received at least one life-saving intervention and were considered priority one, with advanced airway intervention (59.5\%) predominating. Additional study characteristics are provided in table 3.

The SPTT demonstrated the greatest sensitivity in determining priority one status $(92.2 \%, 95 \%$ CI $90.5 \%$ to $93.7 \%)$, followed by the MPTT-24 $(80.8 \%, 95 \%$ CI $78.4 \%$ to $83.0 \%)$. The performance of the SPTT represents an absolute increase in sensitivity of 47.2\%-58.1\% over other tools (PTT-34.1\% (95\% CI 31.4\% to $36.9 \%)$, JumpSTART-45.0\% (95\% CI $42.1 \%$ to $47.8 \%)$ ). This high sensitivity was correlated with low rates of undertriage $(7.8 \%$ and 19.2\%, respectively, for the SPTT and MPTT-24), but at the expense of higher rates of overtriage $(75.0 \%$ and $70.2 \%)$ corresponding to specificities of $12.1 \%$ and $39.6 \%$, respectively. Full test characteristics (including overtriage and undertriage rates) of all triage tools in the primary analysis are shown in table 4A with summary results shown in online supplemental table 2.

For detecting major trauma, the SPTT demonstrated the highest sensitivity $(91.8 \%, 95 \%$ CI $90.3 \%$ to $93.1 \%)$ followed by the MPTT-24 (75.6\%, 95\% CI 73.5\% to 77.7\%), with both PTT and JumpSTART demonstrating much lower sensitivity (28.8\%, $95 \%$ CI $26.6 \%$ to $31.0 \%$; and $36.0 \%$, 95\% CI $33.7 \%$ to $38.4 \%$, respectively). For mortality, the SPTT, MPTT-24 and JumpSTART all had comparable sensitivities (83.0\%-88.7\%), outperforming the PTT $(71.7 \%, 95 \%$ CI $57.7 \%$ to $83.2 \%)$. The full test characteristics for the secondary outcomes are provided in table $4 B, C$.

\section{Subgroup analysis by age category}

The SPTT demonstrated a high sensitivity across all age groups (89.3\%-96.3\%), with its lowest in the 5-12 years age group. 


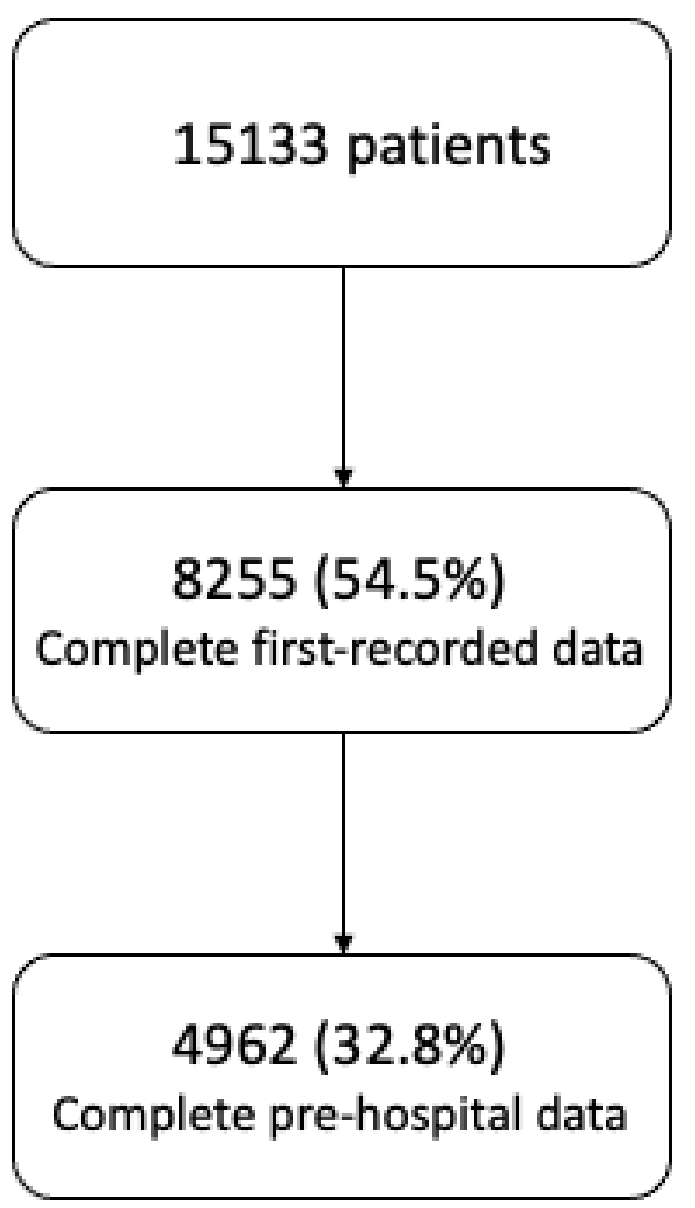

Figure 1 Study flow diagram.

The performance of PTT reduced as age increased, exhibiting the lowest sensitivity $(20.8 \%, 95 \%$ CI $14.8 \%$ to $28.4 \%)$ for the 12-16 years age group. By contrast, the performance of JumpSTART varied between the age groups and did not demonstrate a consistent trend. In the oldest age group (12-16 years), the MPTT-24 demonstrated the greatest sensitivity $(98.0 \%, 95 \% \mathrm{CI}$ $93.8 \%$ to $99.5 \%$ ) and apart from the SPTT, the remaining paediatric triage tools showed the worst performance across all age groups against which they were assessed. This subgroup analysis is provided in detail in online supplemental table 3.

\section{Secondary analysis}

First recorded physiological data (including prehospital and ED) were available for 8255 patients $(54.5 \%)$. Within this cohort, the median age was 10.4 years (IQR 5.2-13.7) with men continuing to account for the majority of cases $(68.7 \%)$. The outcome and median ISS remained unchanged (1.1\% mortality, median ISS 9 (IQR 9-17)) to the primary analysis. A comparable proportion
(16.3 vs $17.6 \%$ ) received at least one life-saving intervention, with advanced airway intervention again predominating $(60.1 \%)$.

Tool performance was largely similar to the primary analysis, with the SPTT exhibiting the highest sensitivity $(90.0 \%, 95 \%$ CI $88.5 \%$ to $91.2 \%)$, followed by the MPTT-24 (81.2\%, 95\% CI $79.5 \%$ to $82.9 \%$ ). The full secondary analysis test characteristics are provided in online supplemental table 4.

\section{Missing data}

A significant proportion of patients had incomplete prehospital physiological data $(n=10171,67.2 \%)$. Those with missing data were significantly younger (median age 3.9 vs $11.9, \mathrm{p}<0.0001$ ). While no difference was observed in median ISS, the outcome differed between the two groups with a higher mortality in those excluded $(3.1 \%$ vs $1.1 \%, \mathrm{p}<0.0001)$. Additionally, the leading mechanisms of injury were 'reversed' between the complete (motor vehicle collision 49.6\%, low falls 23.9\%) and incomplete data groups (motor vehicle collision $22.2 \%$, low falls $47.5 \%$ ).

Performance characteristics were unchanged following multiple imputation to account for missing data. The full test characteristics are provided in online supplemental table $4 \mathrm{~b}$,c.

\section{DISCUSSION}

Using a large civilian trauma registry, we have validated the performance accuracy of the novel SPTT and compared it with existing adult and paediatric triage tools in identifying the need for life-saving interventions in a UK paediatric population. The SPTT (a specific paediatric tool) and the MPTT-24 (an adult triage tool) are the most accurate at predicting need for lifesaving intervention, major injury and mortality in the paediatric population.

While there has been much recent focus on defining the optimal major incident triage tool for adult patients, this has not yet been the case for children. Few bespoke paediatric triage tools have been derived and there are minimal data from external validations to support the use of one over another on the basis of performance characteristics. ${ }^{2}{ }^{15}{ }^{23-25}$ While previous studies have compared triage tool performance using either mortality or ISS, neither of these are likely to extrapolate well to the acuity of the patient while in the prehospital setting. ${ }^{2-4}$ In a major incident, the purpose of triage is to prioritise those patients who may benefit from life-saving interventions. ${ }^{25} 26$ This outcome measure should therefore form the primary outcome of interest in the assessment of any such tool. The performance accuracy of the triage tools assessed in this study was further delineated using subgroup analysis by age range, and extended to the secondary outcomes of major trauma and mortality.

The first paediatric tool, PTT, ${ }^{6}$ was developed to prevent overtriage when the adult Triage Sieve was used on paediatric patients. In a previous comparative analysis, PTT showed high specificity (>98\%) for identifying patients who either required life-saving interventions or who had sustained major trauma (ISS >15).

\begin{tabular}{|c|c|c|c|c|c|c|}
\hline Age & Under 1 & $1-2$ years & $2-5$ years & $5-12$ years & $12-16$ years & \\
\hline Frequency $(n(\%))^{*}$ & $2072(13.7)$ & $1261(8.3)$ & $3045(20.1)$ & $4572(30.21)$ & $4183(27.6)$ & $\mathrm{N}=15133(100 \%)$ \\
\hline Complete prehospital physiology ( $(\%))$ & $145(2.9)$ & $59(1.2)$ & $445(9.0)$ & $1915(38.6)$ & $2398(48.3)$ & $\mathrm{N}=4962(32.8 \%)$ \\
\hline Complete first available physiology $(\mathrm{n}(\%)) \dagger$ & $508(24.5)$ & $260(20.6)$ & $1093(35.9)$ & $3095(67.7)$ & $3299(78.9)$ & $\mathrm{N}=8255(54.5 \%)$ \\
\hline Complete first available physiology $(\mathrm{n}(\%)) \ddagger$ & $1178(56.7)$ & $675(53.5)$ & $2044(67.1)$ & $3755(82.1)$ & $3631(86.8)$ & $\mathrm{N}=11283(74.6 \%)$ \\
\hline
\end{tabular}

*Overall study population age $<16$ years, $n=15133$.

†Complete first available physiological data (ED and prehospital physiological data).

‡Complete first available physiological data (ED and prehospital physiological) using imputed data. 
Table 3 Characteristics of study population

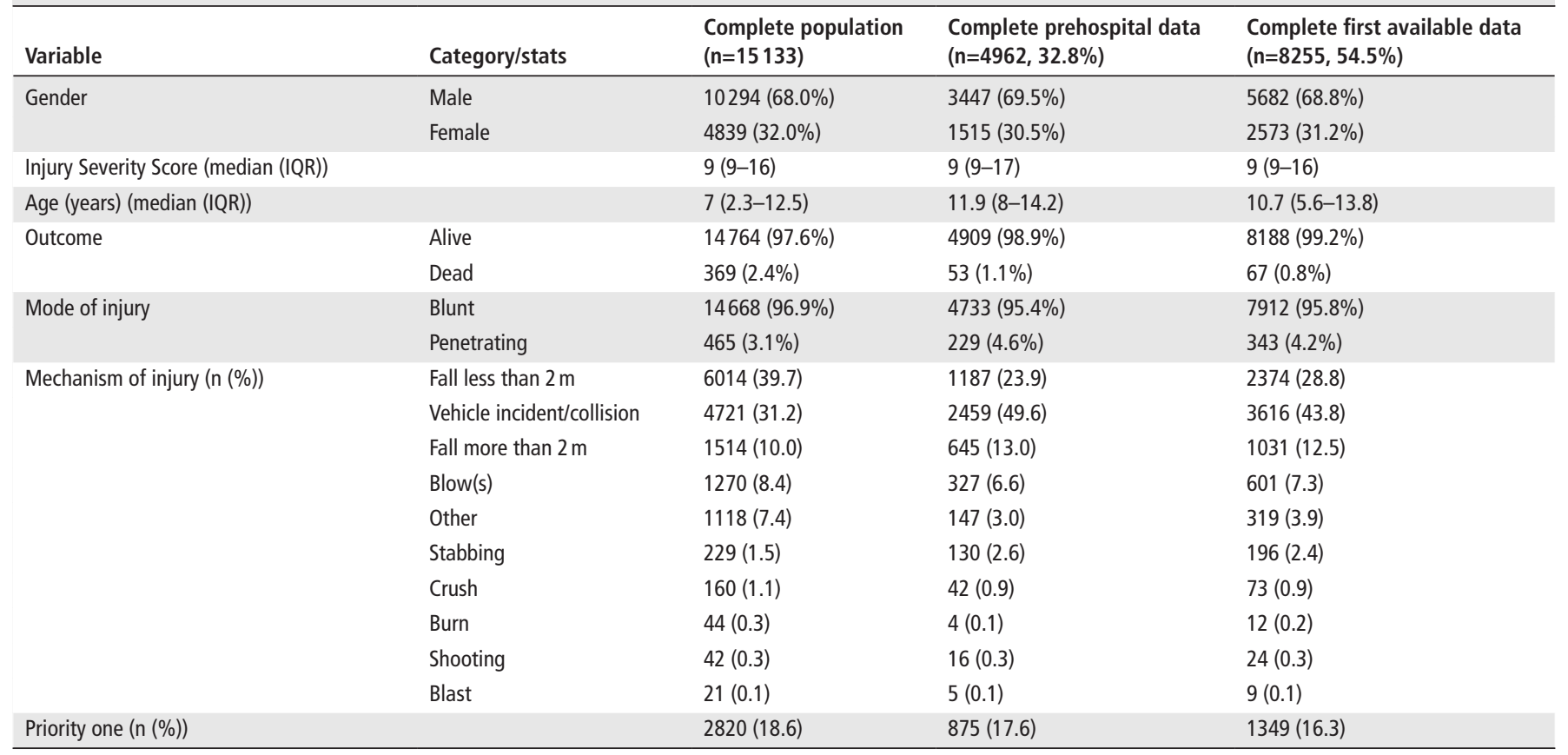

However, despite good specificity, the tool demonstrated poor sensitivity for both outcomes, corresponding to undertriage rates in excess of $58 \% .^{2}$ In the same study, JumpSTART, while also performing with high specificity (>97\%), demonstrated less than $5 \%$ sensitivity for both outcomes, correlating with undertriage rates in excess of $95 \% .^{2}$ A further study used trauma registry data to assess performance accuracy of triage tools in predicting mortality and major trauma, and reported similar sensitivity levels for the PTT but considerably lower specificity (66.0\% and 66.5\%, respectively). By contrast, JumpSTART demonstrated better performance. ${ }^{23}$ With life-saving intervention being our primary outcome measure, our study aligns more closely to the former study, and while we report a comparable performance in sensitivity for the PTT $(37.3 \%$ vs $41.5 \%)$, the JumpSTART method exhibited improved performance against our data set (45.3\% vs $0.8 \%){ }^{2}$

The key principles of triage are that it should be rapid, reliable and reproducible, irrespective of the provider performing it. ${ }^{1}$ The reliability of the triage tool is the assessment of its performance; key to which is identifying those in need of life-saving interventions and minimising undertriage (the misclassification of patients as not needing a life-saving intervention). In an ideal setting, the triage tool used would minimise both undertriage and overtriage, but the reality is that increasing sensitivity often corresponds to decreasing specificity necessitating a decision over their importance. An additional factor, when assessing triage methods, lies with their application simplicity; an overly complex triage system with good performance may not be practical, particularly within prehospital settings. While the SPTT demonstrated the highest overall sensitivity in our study, the inclusion of five age categories with different physiological variables is unlikely to make it a practical option for use in either prehospital settings or in surge situations within hospital settings.

Specific paediatric tools also differ in the ages in which the tools are recommended (JumpSTART ${ }^{7}$ and the PTT $^{6}$ differ in their approach, recommending cut-offs at 8 and 12 years, respectively). For example, the subgroup analysis of the 12-16years age group in this study demonstrates directly comparable median physiological parameters with that observed in a previous adult major incident triage study, which would support the approach taken by the PTT. ${ }^{627}$

One potential solution is the application of a single tool across all age ranges, covering adult and paediatric patients. This may need to involve a compromise between optimal tool performance, practicality and ease of use. The adoption of single physiological thresholds, such as those used in the MPTT-24, ${ }^{9}$ represents a more simplistic option and will convey additional benefit from the perspective of familiarity and training. However, as observed within the MPTT-24 performance analysis, while this reduces undertriage, it is associated with increased overtriage, although comparable with that tolerated within the adult setting.

\section{Limitations}

A key limitation of our work lies with the use of a retrospective trauma database. First, the mechanism of injury encountered on the database (road traffic collisions and low falls) is unlikely to accurately represent the injury pattern encountered following a major incident in its totality. Ideally, any analysis of triage tools should be performed in the environment in which they are designed to function but owing to the unpredictable nature of major incidents, this is both impractical and also largely unethical as well as unrealistic given the frequency of paediatric major incidents. As a result, trauma databases are frequently used as a surrogate, allowing for the analysis of a large number of seriously injured patients. ${ }^{91415}$ A further limitation is the presence of inclusion criteria for entry into the TARN database; while only a minority of patients $(17.6 \%)$ received a life-saving intervention in our analysis, the inclusion criteria will likely skew the study population towards those with more severe injuries. Therefore, it would be anticipated that the frequency of patients not receiving a life-saving intervention in the population will be higher than observed in this study.

We also acknowledge that the exclusion of patients with incomplete physiological data is an additional limitation of our study, with only $32.8 \%$ having complete prehospital data with which 


\begin{tabular}{|c|c|c|c|c|}
\hline \multicolumn{5}{|c|}{ (A) Life-saving interventions, $\mathrm{n}=4962(32.8 \%)$} \\
\hline Tool & Sensitivity & Specificity & Undertriage & Overtriage \\
\hline SPTT & 92.2 (90.5 to 93.7$)$ & $12.1(11.1$ to 13.2$)$ & $7.8 \%$ & $75.0 \%$ \\
\hline PTT & 34.1 (31.4 to 36.9$)$ & $85.8(84.6$ to 86.9$)$ & $65.9 \%$ & $56.7 \%$ \\
\hline JumpSTART & $45.0(42.1$ to 47.8$)$ & 92.1 (91.1 to 92.9) & $55.1 \%$ & $35.7 \%$ \\
\hline MPTT-24 & $80.8(78.4$ to 83.0$)$ & 39.6 (38.0 to 41.2$)$ & $19.2 \%$ & $70.2 \%$ \\
\hline Careflight & $44.4(41.5$ to 47.2$)$ & 94.9 (94.1 to 95.6$)$ & $55.6 \%$ & $26.7 \%$ \\
\hline MIMMS & 41.6 (38.8 to 44.5$)$ & 79.6 (78.3 to 80.9) & 58.4 & $60.7 \%$ \\
\hline NASMeD & $51.9(49.0$ to 54.7$)$ & 79.1 (77.8 to 80.4$)$ & $48.1 \%$ & $55.9 \%$ \\
\hline RAMP & 43.8 (41.0 to 46.6$)$ & 94.9 (94.1 to 95.6$)$ & $56.2 \%$ & $26.8 \%$ \\
\hline MSTART & $53.9(51.0$ to 56.7$)$ & 88.1 (87.0 to 89.1$)$ & $46.1 \%$ & $41.0 \%$ \\
\hline \multicolumn{5}{|c|}{ (B) ISS > 15, n=4962 (32.8\%) } \\
\hline Tool & Sensitivity & Specificity & Undertriage & Overtriage \\
\hline SPTT & $91.8(90.3$ to 93.1$)$ & $12.4(11.3$ to 13.6$)$ & $8.2 \%$ & $66.4 \%$ \\
\hline PTT & $28.8(26.6$ to 31.0$)$ & 85.7 (84.5 to 86.9$)$ & $71.2 \%$ & $50.7 \%$ \\
\hline JumpSTART & 36.0 (33.7 to 38.4$)$ & 92.4 (91.4 to 93.3) & $64.0 \%$ & $30.5 \%$ \\
\hline MPTT-24 & 75.6 (73.5 to 77.7$)$ & 39.6 (38.0 to 41.3 ) & $24.4 \%$ & $62.3 \%$ \\
\hline Careflight & 34.9 (32.6 to 37.3$)$ & 95.2 (94.4 to 95.9 ) & $65.1 \%$ & $22.1 \%$ \\
\hline MIMMS & 34.9 (32.6 to 37.3$)$ & 79.0 (77.6 to 80.4$)$ & $65.1 \%$ & $55.4 \%$ \\
\hline NASMeD & $42.6(40.2$ to 45.1$)$ & 78.5 (77.1 to 79.9$)$ & $57.4 \%$ & $51.1 \%$ \\
\hline RAMP & 34.5 (32.2 to 36.9$)$ & 95.3 (94.5 to 96.0$)$ & $65.5 \%$ & $22.1 \%$ \\
\hline MSTART & 42.2 (39.8 to 44.7$)$ & 87.7 (86.6 to 88.8 ) & $57.8 \%$ & $37.5 \%$ \\
\hline \multicolumn{5}{|c|}{ (C) Mortality, n=4962 (32.8\%) } \\
\hline Tool & Sensitivity & Specificity & Undertriage & Overtriage \\
\hline SPTT & 86.8 (74.7 to 94.5$)$ & $11.0(10.2$ to 12.0$)$ & $13.2 \%$ & $92.2 \%$ \\
\hline PTT & 71.7 (57.7 to 83.2 ) & 81.6 (80.5 to 82.6$)$ & $28.3 \%$ & $96.0 \%$ \\
\hline JumpSTART & 88.7 (77.0 to 95.7$)$ & 83.9 (82.9 to 84.9$)$ & $11.3 \%$ & $94.4 \%$ \\
\hline MPTT-24 & 83.0 (70.2 to 91.9$)$ & 34.9 (33.5 to 36.2$)$ & $17.0 \%$ & $98.6 \%$ \\
\hline Careflight & 71.7 (57.7 to 83.2 ) & $86.0(85.0$ to 87.0$)$ & $28.3 \%$ & $94.7 \%$ \\
\hline MIMMS & 71.7 (57.7 to 83.2 ) & 75.0 (73.8 to 76.2 ) & $28.3 \%$ & $97.0 \%$ \\
\hline NASMeD & 71.7 (57.7 to 83.2 ) & 72.1 (70.8 to 73.4$)$ & $28.3 \%$ & $97.2 \%$ \\
\hline RAMP & 69.8 (55.7 to 81.7 ) & 86.2 (85.2 to 87.1 ) & $30.2 \%$ & $94.8 \%$ \\
\hline MSTART & 81.1 (68.0 to 90.6 ) & 78.6 (77.4 to 79.8 ) & $28.9 \%$ & $96.1 \%$ \\
\hline
\end{tabular}

ISS, Injury Severity Score; MIMMS, Major Incident Medical Management and Support; MPTT-24, Modified Physiological Triage Tool-24; MSTART, Modified Simple Triage and Rapid Treatment; NASMeD, National Ambulance Service Medical Directors; PTT, Paediatric Triage Tape; RAMP, Rapid Assessment of Mentation and Pulse; SPTT, Sheffield Paediatric Triage Tool.

to perform the primary analysis. While median ISS is comparable between the included and excluded groups, we did observe a difference in median age and outcome, with those patients in the excluded group being younger and having a higher mortality. In an attempt to mitigate for the missing prehospital data, additional analyses were conducted using first recorded physiological data (including ED data) and also on an imputed data set. However, even this is imperfect as physiology may have changed by arrival to ED in response to any interventions performed in the prehospital setting. Performance characteristics of the triage tools were unchanged in these further analyses.

\section{CONCLUSION}

In this comparative analysis of paediatric triage tools, the SPTT and MPTT-24 perform better than existing paediatric triage tools for identifying those patients requiring life-saving intervention. This may necessitate a change in recommended practice. Further work is required to determine the optimum method of paediatric major incident triage, but consideration should be given to simplifying major incident triage by the use of one generic tool (the MPTT-24) for adults and children.

\section{Author affiliations}

${ }^{1}$ Institute of Naval Medicine, Gosport, UK

${ }^{2}$ Academic Department of Military Emergency Medicine, Royal Centre for Defence Medicine, Birmingham, UK

${ }^{3}$ NIHR Surgical Reconstruction and Microbiological Research Centre (SRMRC), Heritage Building, Queen Elizabeth Hospital, Birmingham, UK

${ }^{4}$ Centre for Computational Biology, Institute of Cancer and Genomic Sciences, University of Birmingham, Birmingham, UK

${ }^{5}$ Department of Anaesthesia, University Hospitals Birmingham, Birmingham, UK ${ }^{6}$ Institute of Translational Medicine, University Hospitals Birmingham NHS Foundation Trust, Birmingham, UK

${ }^{7}$ MRC Health Data Research UK (HDR UK), Birmingham, UK

${ }^{8}$ Emergency Department, Bristol Royal Children's Hospital, Bristol, UK

${ }^{9}$ Emergency Department, University Hospitals Plymouth NHS Trust, Plymouth, UK

Twitter James Vassallo @jamievassallo and Mark D Lyttle @mdlyttle

Acknowledgements The authors thank Professor Fiona Lecky (research director) and Antoinette Edwards (chief executive officer) at Trauma Audit Research Network (TARN) for facilitating access to the TARN Database.

Contributors JV, MDL and JS designed the study. JV, SC, NM and YX verified the underlying data. JV and SC conducted the analysis. All authors contributed to data interpretation. JV wrote the initial draft of the manuscript. All authors contributed to initial critical revisions of the manuscript. JV takes responsibility for the manuscript as a whole and acts as the article guarantor.

Funding This study is funded by the National Institute for Health Research (NIHR) Surgical Reconstruction and Microbiology Research Centre. GG also acknowledges support from the MRC Heath Data Research UK (HDRUK/CFC/01). Additionally, the lead author received an RCEM Young Investigator grant to support open-access publication fees for the study.

Competing interests None declared.

Patient consent for publication Not required.

Ethics approval TARN has ethical approval (Section 251) for research on anonymised data.

Provenance and peer review Not commissioned; externally peer reviewed.

Data availability statement Data may be obtained from a third party and are not publicly available.

Supplemental material This content has been supplied by the author(s). It has not been vetted by BMJ Publishing Group Limited (BMJ) and may not have been peer-reviewed. Any opinions or recommendations discussed are solely those of the author(s) and are not endorsed by BMJ. BMJ disclaims all liability and responsibility arising from any reliance placed on the content. Where the content includes any translated material, BMJ does not warrant the accuracy and reliability of the translations (including but not limited to local regulations, clinical guidelines, terminology, drug names and drug dosages), and is not responsible for any error and/or omissions arising from translation and adaptation or otherwise.

Open access This is an open access article distributed in accordance with the Creative Commons Attribution Non Commercial (CC BY-NC 4.0) license, which permits others to distribute, remix, adapt, build upon this work non-commercially, and license their derivative works on different terms, provided the original work is properly cited, appropriate credit is given, any changes made indicated, and the use is non-commercial. See: http://creativecommons.org/licenses/by-nc/4.0/.

\section{ORCID iDs}

James Vassallo http://orcid.org/0000-0001-9783-165X

Mark D Lyttle http://orcid.org/0000-0002-8634-7210

Jason Smith http://orcid.org/0000-0002-6143-0421

\section{REFERENCES}

1 Advanced Life Support Group. Major incident medical management and support: the practical approach at the scene. London: BMJ Books, 2011

2 Wallis LA, Carley S. Comparison of paediatric major incident primary triage tools. Emerg Med J 2006;23:475-8.

3 Baxt WG, Upenieks V. The lack of full correlation between the injury severity score and the resource needs of injured patients. Ann Emerg Med 1990;19:1396-400.

4 Vassallo J, Fuller G, Smith JE. Relationship between the injury severity score and the need for life-saving interventions in trauma patients in the UK. Emerg Med J 2020;37:502-7.

5 Schultz $\mathrm{CH}$. Comparing disaster triage algorithms: selecting the right metric. Ann Emerg Med 2013;62:642-3.

6 Hodgetts TJ. Paediatric triage tape. Prehospital Immediate Care 1998;2:155-9.

7 Romig LE, triage P. Pediatric triage. A system to JumpSTART your triage of young patients at MCIs. JEMS 2002;27:52-8 
8 Kahn CA, Schultz CH, Miller KT, et al. Does START triage work? An outcomes assessment after a disaster. Ann Emerg Med 2009;54:424-30.

9 Vassallo J, Smith JE, Wallis LA. Major incident triage and the implementation of a new triage tool, the MPTT-24. J R Army Med Corps 2018;164:103-6.

10 NHS England. Clinical guidelines for major incidents and mass casualty events. Version 2, 2020. Available: https://www.england.nhs.uk/wp-content/uploads/2018/ 12/B0128-clinical-guidelines-for-use-in-a-major-incident-v2-2020.pdf [Accessed 2 May 2021].

11 Heffernan RW, Lerner EB, McKee CH, et al. Comparing the accuracy of mass casualty triage systems in a pediatric population. Prehosp Emerg Care 2019;23:304-8.

12 Advanced Life Support Group. Advanced paediatric life support. London: BMJ Books, 2016.

13 Vassallo J, Beavis J, Smith JE, et al. Major incident triage: derivation and comparative analysis of the modified physiological triage tool (MPTT). Injury 2017;48:992-9.

14 Garner A, Lee A, Harrison K, et al. Comparative analysis of multiple-casualty incident triage algorithms. Ann Emerg Med 2001;38:541-8.

15 Cross KP, Cicero MX. Head-to-head comparison of disaster triage methods in pediatric, adult, and geriatric patients. Ann Emerg Med 2013;61:668-76.

16 Lerner EB, McKee CH, Cady CE, et al. A consensus-based gold standard for the evaluation of mass casualty triage systems. Prehosp Emerg Care 2015;19:267-71.

17 NHS England Emergency Preparedness Resilience Response EPRR Clinical Reference Group. 'Triage'. Minutes of NHS England 5 June 2019. Leeds: NHS England, 2019.

18 NARU. NARU input to new triage sieve, 2014. Available: https://naru.org.uk/naruinput-to-new-triage-sieve/ [Accessed 12 May 2021].
19 Cross KP, Petry MJ, Cicero MX. A better START for low-acuity victims: data-driven refinement of mass casualty triage. Prehosp Emerg Care 2015;19:272-8.

20 Bennett A. Methodologies utilized and lessons learned in high threat environments and mass casualty environments. JHTAM 2019:1-7.

21 Peng J, Xiang H. Trauma undertriage and overtriage rates: are we using the wrong formulas? Am J Emerg Med 2016:34:2191-2.

22 Rehn M, Eken T, Krüger AJ, et al. Precision of field triage in patients brought to a trauma centre after introducing trauma team activation quidelines. Scand I Trauma Resusc Emerg Med 2009;17:1.

23 Price CL, Brace-McDonnell SJ, Stallard N, et al. Performance characteristics of five triage tools for major incidents involving traumatic injuries to children. Injury 2016;47:988-92.

24 Donofrio JJ, Kaji AH, Claudius IA, Chang TP, et al. Development of a pediatric mass casualty triage algorithm validation tool. Prehosp Emerg Care 2016:20:343-53.

25 Cicero MX, Overly F, Brown L, et al. Comparing the accuracy of three pediatric disaster triage strategies: a simulation-based investigation. Disaster Med Public Health Prep 2016;10:253-60

26 Vassallo J, Smith JE, Bruijns SR, et al. Major incident triage: a consensus based definition of the essential life-saving interventions during the definitive care phase of a major incident. Injury 2016;47:1898-902.

27 Vassallo J, Smith J, Bouamra 0, et al. The civilian validation of the modified physiological triage tool (MPTT): an evidence-based approach to primary major incident triage. Emerg Med J 2017:34:810-5. 